\title{
Irradiation effects and consequences on in - service properties under proton and neutron mixed spectra: An overview
}

\author{
P. Jung
}

\author{
Institut für Festkörperforschung, Forschungszentrum Jülich, 52425 Jülich, Germany
}

\section{Extended Abstract ${ }^{+}$}

Spallation reactions, induced by protons in the GeV energy range in high- $Z$ targets are considered for a variety of applications [2]: production of neutrons for scattering (e.g. the European Spallation Source ESS) or for breeding nuclear fuel, production of tritium or elementary particles, transmutation of nuclear waste (e.g. the European Accelerator Driven System ADS), etc. Most of the recent projects employ targets of heavy liquid metals $(\mathrm{Hg}, \mathrm{PbBi}, \mathrm{Pb}$, etc.) which, aside from advantages in cooling, minimize radiation damage, essentially restricting it to container and window materials. As the limited amount of irradiations in spallation environments is mostly restricted to relatively low doses, results from previous material development programmes will have to be adopted in material selection for the planned high power sources. For this purpose, differences

Table 1. Systematics of irradiation damage.

\begin{tabular}{|l|l|l|l|}
\hline \multicolumn{1}{|c|}{ Defects: } & Structural & Microchemical & Bulk composition \\
\hline Atomic process & Atomic displacements & $\begin{array}{l}\text { Radiation enhanced } \\
\text { diffusion }\end{array}$ & Transmutation \\
\hline Microstructure & $\begin{array}{l}\text { Defect clusters } \\
\text { Dislocations } \\
\text { Voids }\end{array}$ & $\begin{array}{l}\text { Segregation } \\
\text { Precipitates }\end{array}$ & $\begin{array}{l}\text { Composition changes } \\
\text { Helium bubbles }\end{array}$ \\
\hline $\begin{array}{l}\text { Macroscopic } \\
\text { property damage }\end{array}$ & $\begin{array}{l}\text { Hardening } \\
\text { Irradiation embrittlement } \\
\text { Swelling } \\
\text { Irradiation creep }\end{array}$ & $\begin{array}{l}\text { Corrosion } \\
\text { IASCC } \\
\text { LME (Irradiation) }\end{array}$ & $\begin{array}{l}\text { H-embrittlement } \\
\text { Low-T He-embrittlement } \\
\text { High-T He-embrittlement }\end{array}$ \\
\hline
\end{tabular}

\footnotetext{
${ }^{+}$) An extended account on irradiation effects on material properties has been presented at the $2^{\text {nd }}$ International Workshop on Materials for Hybnd Reactors and Related Technologies ENEA-Centro CIEB, Brasimone, Italy, 2001, and is in press for J.Nucl.Mater (2001) [1].
} 
between the various particle spectra have to be taken into account. From a systematic view, three classes of irradiation induced defects can be distinguished, namely structural, microchemical and changes in bulk composition, with corresponding consequences for microstructure and macroscopic properties (table I).

The cross sections for atomic displacement as well as those for production of light elements $(\mathrm{H}, \mathrm{He})$ become virtually equal for protons and neutrons above about $20 \mathrm{MeV}$ [1]. This means that the high energy protons in a spallation source induce no qualitatively new processes compared to neutrons. But in comparison to fast fission or fusion reactors, the energies of the irradiation particles (protons and neutrons) are much higher, with the following consequences'

1. harder spectrum of atomic recoils, causing larger average sizes of displacement cascades,

2. higher production rates of transmutants (manly hydrogen and helium), and

3. production of other atomic species from spallation debris

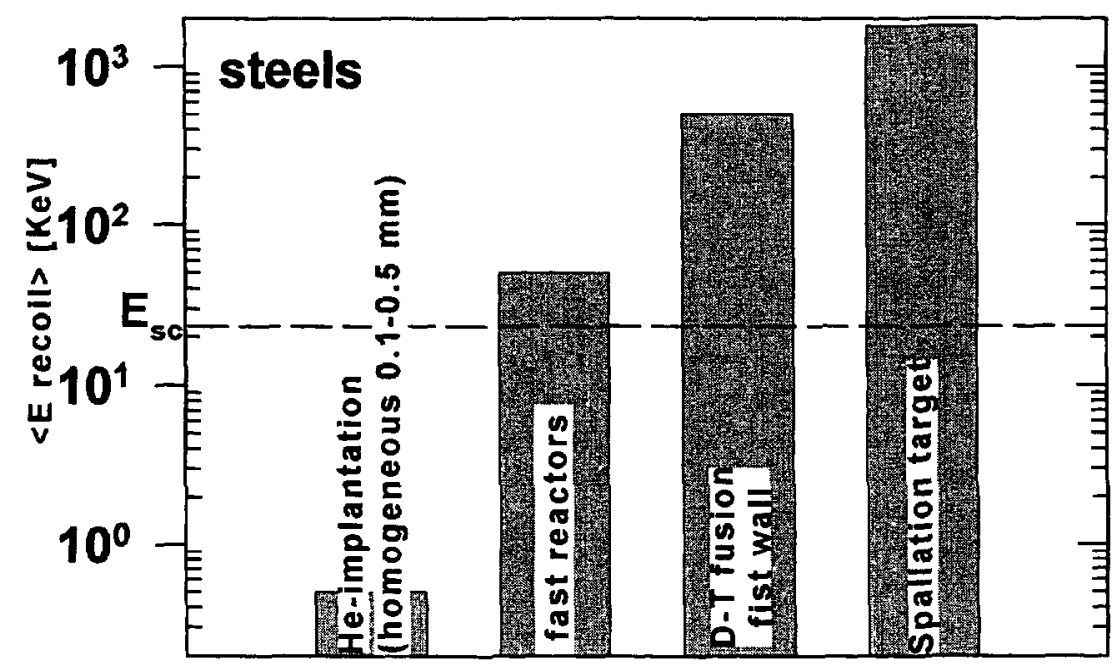

Figure 1. Average recoil energies from a spallation spectrum, as well as those fom fast-fission and fusion, are above the on-set of subcascade formation, while light cons, examplified for helium implantation stay far below this level.

Experimental observations indicate that at recoil energies above typically $25 \mathrm{keV}\left(\mathrm{E}_{\mathrm{sc}}\right.$ in Fig.l), displacement cascades do not increase in size anymore, but tend to split up into subcascades of virtually constant size. This means that the high energy particles in a spallation source will not produce a qualitatively different type of structural damage, but only a locally more dense arrangement of subcascades may result. On the other hand the much higher concentration of light transmutation products seems to cause qualitatively new effects. Especially at lower temperatures, both helium and also hydrogen are retained [3] and cause severe embrittlement, which seems to increase or to decrease with increasing strain rate respectively. Qualitatively new effects must also be expected from the production of other atomic species. While reactor neutrons produce, aside from the light transmutants $\mathrm{H}$ and $\mathrm{He}$, only a limited number of atomic species which are neighbouring the target atoms in the periodic system, spallation produces atoms of a large variety of $Z$. This debris probably poses no problem in the liquid metal, as their concentration will remain below the solubility limit, and thus will not precipitate to form for example abrasive particles.

But in the structural materials some if these elements may exceed the solubility limit and segregate or form precipitates with severe consequences for material integrity. For steels the deleterious effect of small amounts of elements like $\mathrm{P}, \mathrm{S}$ etc. is well known, but many others will be produced which are not common in standard steels, and the effect of which is largely unknown. The 
range of homologuous temperatures where some of the yet identified irradiation effects occur are listed in Figure 3 and discussed in detall in Ref.[1]. It is also indicated which of these effects affect primarily austenitic (italic) or ferritic/martensitic (block) steels. The intended opcrational temperatures of ESS and ADS show that austenitic and martensitic steels seem more suited for application at lower and higher temperatures, respectively. Of course, other considerations such is strength, compatibility with coolants (liquid metals and others), etc. have also to be taken itto account in selecting structural materials for a specific device.

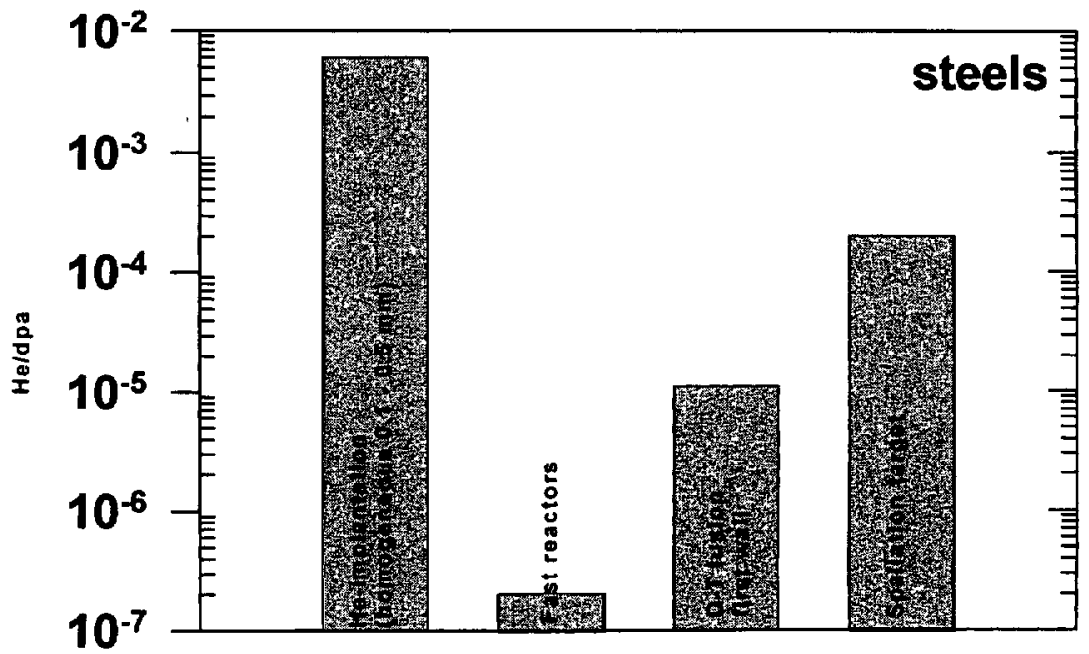

Figure 2. Ratios of production cross-sections for helium and atomic displacements in steel in different environments. The situation for spallation is more closely matched by implantation than by fast rcactor irradiation.

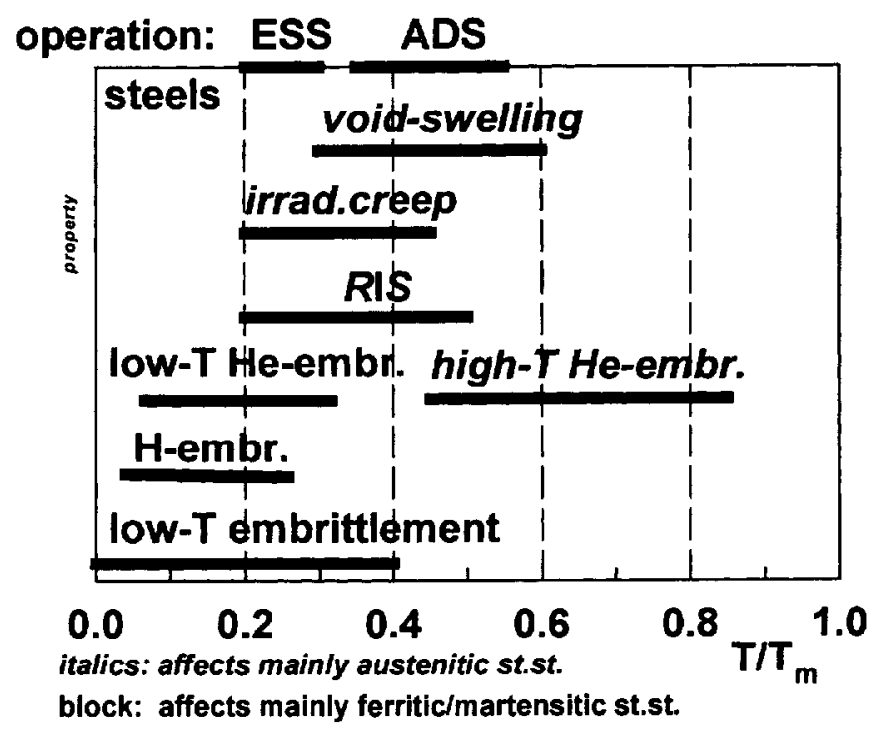

Figure 3. Schematic view of homologuous temperature ranges of irradiation induced changes of mechanical properties. 
In Ref.[1] it was concluded that embrittlement by irradiation and probably also by helium are presently identified as the most severe problems, while other topics such as the production of uncommon atomic species, interaction with the liquid metals under irradiation, and, if applicable (e.g. ESS), additional high-cycle-fatigue load, urgently need more investigation.

\section{REFERENCES}

[1] P. Jung, J. Nucl. Mater., (2001) in press.

[2] G.S. Bauer, Nucl. Instr. Meth. Phys. Res. A 463 (2001) 505.

[3] P. Jung, C. Liu and J. Chen, J. Nucl. Mater., 296 (2001) 165. 